Rev. Saúde pübl., s. Paulo

7:251-72, 1973.

\title{
BISSINOSE NO MUNICÍPIO DA CAPITAL DO ESTADO DE SÃO PAULO, BRASIL *
}

\author{
Diogo Pupo NOGUEIRA** \\ Berenice F. GOELZER *** \\ Joe W. COX *** \\ Edgar Pereira da SILVA **** \\ Naim SAUAIA *****
}

RSPU-B $/ 176$

Nogueira, D. P. et al. - Bissinose no município da capital do Estado de

S. Paulo, Brasil. Rev. Saúde públ., S. Paulo, 7: 251-72, 1973.

Resumo: Seguindo-se uma sistemática epidemiológica, foram estudados os trabalhadores de 3 fiações de algodão, com diferentes quantidades de poeira de algodão em suspensão na atmosfera dos locais de trabalho, comparando-se com 135 pessoas do grupo controle não exposto a essas poeiras. Pelas respostas ao questionário padrão internacional sobre doenças respiratorias, verificou-se que os trabalhadores das fábricas, onde era mais elevada a concentração de poeira de algodão, apresentavam um ou mais sintomas característicos da bissinose; por outro lado, as provas de função pulmonar, realizadas imediatamente antes $e$ após o inicio do trabalho às segundas-feiras, mostravam-se alteradas. Como no grupo controle, verificou-se melhoria significativa da função pulmonar no término do dia de trabalho. E como tal fato nâo foi observado mesmo na fábrica onde a concentração de poeira no ar era muito baixa e onde não se notou piora das provas de função pulmonar entre seus trabalhadores, levantou-se a hipotose de que essa ausência de melhoria possa constituir um sintoma precoce da bissinose.

Unitermos: Bissinose*; Pneumoconiose *; Doenças respiratórias *

* Trabalho conjunto da Faculdade de Saúde Pública da Universidade de São Paulo e da Fundação Centro Nacional de Segurança, Higiene e Medicina do Trabalho.

** Do Departamento de Saúde Ambiental da Faculdade de Saúde Pública da USP - Av. Dr. Arnaldo, 715 - Săo Paulo, S.P. - Brasil.

*** Da Divisão de Higlene do Trabalho da Fundaçăo Centro Nacional de Segurança, Higiene e Medicina do Trabalho - Rua Cardoso de Almelda, 520 - Sáo Paulo, S.P. - Brasil.

**** Da Divisão de Medicina do Trabalho da Fundação Centro Nacional de Segurança, Higiene e Medicina do Trabalho - Rut Cardoso de Almeida, 520 - Sáo Paulo. S.P. - Brasil.

***** Do Departamento de Medicina Preventiva da Faculdade de Medicina da Universidade de São Paulo - Av. Dr. Arnaldo, 455 - São Paulo, S.P. - Brasil. 
NOGUEIRA, D. P. et al. - Bissinose no município da capital do Estado de são Paulo, Brasil. Rev. Saúde públ., s. Paulo, 7:251-72, 1973.

\section{NTRODU C Ã O}

Como o descreve Schilling 9, 10, desde o início do século XIX sabia-se, na Inglaterra, que os operários de fiaçóes de algodão costumavam apresentar doença respiratória caracterizada, nas suas fases iniciais, por uma sensação de constrição torácica que aparecia caracteristicamente às segundas-feiras, logo após o início do trabalho; com o decorrer do tempo, tal sensação se estendia para os demais dias da semana, e posteriormente, acompanhava-se de tosse e expectoração abundante.

Tais queixas dos trabalhadores, no entanto, encontravam pouco interesse por parte dos pesquisadores médicos. Realmente, a grande maioria da indústria textil de algodão britânica concentrava-se na área de Lancashire, onde a prevalência da bronquite crônica entre a população em geral é bastante alta; por essa razão, os pesquisadores consideravam que os trabalhadores texteis eram portadores de uma bronquite crônica comum que apenas se agravava pela exposição à poeira de algodão.

Uma série de estudos de morbidade realizados na Inglaterra veio trazer um grande número de dúvidas, que tumultuaram bastante o estudo do problema. $E$ ainda Schilling 10 quem refere o fato de que estatísticas realizadas na década dos 30 pareceram concluir que a morbidade por doenças respiratórias dos trabalhadores de algodão diminuira no período entre 1935 e 1936, quando comparado ao período de 1923 a 1927 , enquanto que parecia estar ocorrendo aumento da morbidade por afecções cárdiocirculatórias entre tais trabalhadores.

Uma revisão dos atestados de óbito veio demonstrar que muitos casos de doença eram de "cor pulmonale"; por- tanto, estavam os pesquisadores atribuindo erroneamente ao aparelho cardiovascular afecções que eram primariamente respiratórias. Tal observações conduziu a um estudo epidemiológico de doenças cardiovasculares, entre os trabalhadores de fiações de algodão, tenđo sido estudados cerca de 250 homens entre 35 e 64 anos de idade; não foram encontradas alterações significativas sob o ponto de vista cardiovascular mas, por outro lado, foi verificado que $66 \%$ dos 131 trabalhadores de cardas e dos batedores queixavam-se exatamente de sensação de constrição torácica, que aparecia às segundas-feiras; além disso, 15 deles apresentavam insuficiência respiratória nítida.

Em face dessa conjuntura, Schilding 10 levou a efeito um estudo epidemiológico sobre doenças respiratórias em 28 fábricas da área de Oldham, na Inglaterra; foram examinados 200 trabalhadores de algodão, todos do sexo masculino, com idade entre 40 e 59 anos e que trabalhavam em cardas e batedores; 100 operários metalúrgicos serviram de grupo controle. De acordo com a história clínica, os trabalhadores foram classificados em três classes: "normais", quanđo não havia sensação de constrição torácica; "grau 1" quando tal sensação aparecia somente às segundas-feiras; e "grau 2" quando tal sensação ocorria tanto na segunda-feira como em outros dias da semana. Cada trabalhador foi estudado por dois observadores diferentes, verificando-se que havia concordância de opinião em $93 \%$ dos casos, havendo discordância apenas na distinção entre os graus 1 e 2 .

Além da anamnese, foi determinado para cada trabalhador o volume máximo de ar expirado em $3 / 4$ de segundo $\left(\mathrm{VEM}_{0,75}\right)$, que se mostrou significante- 
NOGUEIRA, D. P. et al. - Bissinose no municipio da capital do Estado de São Paulo, Brasil. Rev. Saúde pübl., S. Paulo, 7:251-72, 1973.

mente diminuido nos trabalhadores expostos em relação ao grupo controle.

Tais estudos levaram Schilling 10 a concluir que os trabalhadores expostos à poeira de algođão apresentam uma pneumoconiose a bissinose - que pode ser diagnosticada com suficiente precisão pela história clínica e que se associa à diminuição da função ventilatória. Ficou claro que, através da anamnese, é possível demonstrar que a bissinose nas suas fases iniciais não se assemelha à bronquite crônica; assim, muitos dos trabalhadores que tinham sensação de constrição torácica às segundas-feiras não apresentavam tosse e escarro, características desta, que somente aparecem nas fases adiantadas da pneumoconiose; nestas últimas fases, nenhum exame anamnese, exame clínico, exame radiológico, exame funcional ou anátomopatológico - permite mais a diferenciação entre a bissinose $e$ a bronquite crônica.

Estudos posteriores de SchilLing 10 vieram demonstrar que existia correlação de poeira de algodão existente na atmosfera dos locais de trabalho e a incidência da bissinose, tendo sido proposto um limite de tolerância de $100 \mathrm{mg} / 100 \mathrm{~m}^{3}$ de ar. Tal limite foi, posteriormente, considerado pela American Conference of Governamental Industrial Hygienists, que estabeleceu o valor de $1 \mathrm{mg} / \mathrm{m}^{3}$ de ar na sua tabela de limites de tolerância.

A sistemática epidemiológica acima descrita foi aplicada, por diversos autores, em numerosos países e sempre foi possivel observar-se a existência da bissinose em trabalhadores expostos à poeira de algodão, particularmente aqueles que executavam suas funções nos abridores e cardas. Assim, tal tipo de estudo foi realizado, entre outros países, na Austrália 5, Bélgica 11, Egito 4, Grécia 6 e Suécia 1 .
Nos Estados Unidos, durante muito tempo admitia-se a inexistência da bissinose. No entanto, Mc Kerrow \& Schilling 7 e, posteriormente, Bouhurs 2 vieram mostrar, de forma inequívoca, a existência da pneumoconiose também naquele país, como não poderia deixar de ser.

Quanto à fisiopatologia da bissinose, Bounurs 2 é de opinião que a poeira de algodão contém substância farmacologicamente ativa, que provoca constrição brônquica provavelmente através da liberação de histamina. Tal hipótese baseia-se nos seguintes fatos:

1. extratos aquosos de algodão industrial produzem dispnéia e má distribuição do ar inspirado quando inalados, sob a forma de aerosol, por pessoas normais;

2. trabalhadores expostos à poeira de algodão que foi previamente lavado e tratado quimicamente (p. e., algodão para uso medicinal) não apresentam bissinose;

3. em indivíduos normais, a exposição a aerossóis de extrato aquoso de algodão demora de 10 a 20 min. para produzir sintomas.

Por outro lado, uma segunda exposição, 24 horas mais tarde, não causa dispnéia ou alterações funcionais. Este fenômeno de taquifilaxia sugere a presença de substância liberadora de histamina;

4. incubando-se tecido pulmonar humano com extratos de algodão, linho, cânhamo verifica-se a liberação de histamina, o que não ocorre em pulmões de cobaiais, ratos, gatos, carneiros ou porcos.

A substância farmacologicamente ativa é, portanto, específica para a raça humana; 
NOGUEIRA, D. P. et al. - Bissinose no município da capital do Estado de São Paulo, Brasil. Rev. Saúde públ., S. Paulo, 7:251-72, 1973.

5. a administração oral de anti-histamínicos previne as alterações ventilatórias das segundas-feiras.

Ainda segundo BouHurs ${ }^{2}$, a substância farmacologicamente ativa é encontrada nas brácteas, folhas finas e pequenas que se encontram perto do floco de algodão e que frequentemente são encontradas no algodão bruto, que começa a ser processado nas fiações.

Têm sido encontrados, com frequiência, títulos elevados de anticorpos antialgodão em pessoas que trabalham com essa fibra textil; no entanto, títulos significantes são encontrados tanto em portadores de bissinose como em pessoas que não apresentam nenhum sintoma. Não existe, portanto, na gênese da bissinose um processo alérgico pois não há necessidade de sensibilidade prévia e, por outro lado, a maioria das pessoas expostas ao risco são afetadas e não apenas aquelas que apresentam terreno alérgico.

Bissinose no Brasil: Não obstante a indústria textil de algodão ser uma das mais antigas do país e que, durante muitos anos, ocupou o primeiro lugar quanto ao número de trabalhadores empregados, nenhum estudo sobre a possível existência de bissinose entre tais trabalhadores foi levado a efeito. $E$ verdade que peritos judiciais, nomeados pelas varas de acidentes do trabalho, frequientemente argumentavam ter diagnosticado tal pneumoconiose em trabalhadores; no entanto, tratava-se de casos de bronquite crônica típica, que eram rotulados como sendo de bissinose devido exclusivamente ao fato de que seus portadores tinham trabalhado, durante vários anos, em fiações de algodão.

A inexistência de um trabalho epidemiológico sobre o assunto levou-nos a tentar uma pesquisa nesse campo.

\section{MATERIAL E METODO DE ESTUDO}

Foi decidido que o estudo seria feito obedecendo-se à sistemática proposta por Schilling 9. Para tanto, foi obtida a permissão da John B. Pierce Foundation (Yale University, New Haven, Connecticut, U.S.A.) para traduzir o questionário pađrão sobre sintomatologia respiratória estabelecida pelos autores ingleses e devidamente modificada por aquela Fundação; foi utilizado tanto o texto em inglês como o texto espanhol, obtendo-se uma tradução portuguesa de acordo com a terminologia médica e popular do nosso país (Anexo 1).

Para a execução das provas de função pulmonar foi decidido empregar-se $\circ$ aparelho "Vitalograph", de fabricação da firma Vitalograph Limited (Maids Mereton House, Buckhingham, Inglaterra), que é um espirômetro seco, de fácil manejo, que permite a obtenção da capacidade vital forçada (CVF), do volume expiratório máximo no primeiro segundo (VEM $\left.{ }_{1.0}\right)$, da relação deste com a capacidade vital (índice de Tiffeneau), do fluxo expiratório máximo (FEM) e do fluxo médio expiratório (FME).

Foram selecionadas três empresas onde deveria ser levada a cabo a pesquisa. A primeira (fábrica A) era uma fiação de algodão bastante moderna, dotada de eficiente sistema de ventilação local exaustora em toda a sua maquinaria; a segunda (fábrica B) era uma fiação em vias de modernização, na qual se iniciava a colocação de sistemas de ventilação local exaustora, ainđa não em funcionamento; a terceira (fábrica $C$ ) era uma fiação tradicional, sem qualquer sistema de exaustão mas com máquinas colocadas em amplas salas, com satisfatória ventilação natural. Como controle foi utilizada uma indústria de produtos alimentícios, na qual os trabalhadores 
NOGUEIRA, D. P. et al. - Bissinose no município da capital do Estado de São Paulo, Brasil. Rev. Saúde públ., S. Paulo, 7:251-72, 1973.

não se expunham a poeiras de qualquer espécie.

Para a mensuração quantitativa da poeira de algodão em suspensão na atmosfera dos locais de trabalho, por sugestão de Bounurs* foi decidido utilizar-se o elutriador vertical, que recolhe somente a fração respirável da poeira de algodão. Além disso, decidiu-se fazer a coleta da poeira total por intermédio de um precipitador eletrostático. Foram realizadas 8 medidas em cada seção de cađa uma das fábricas examinadas.

A pesquisa foi levada a cabo da seguinte maneira:

1. a quantidade de poeira - total e fração respirável - foi determinada. nas seções de cardas e de preparação das três fábricas;

2. os trabalhadores dessas seções responderam ao questionário padrão sobre sintomatologia respiratória;

3. cada trabalhador foi submetido a duas provas de função pulmonar, ambas realizadas às segundas-feiras: a primeira, imediatamente antes do início do trabalho e a segunda, logo após o término deste.

Para se eliminar ao máximo possível a influência de outros fatores sobre a função pulmonar dos examinados, foi decidido que, tanto no grupo exposto como no grupo controle, somente seriam submetidos às provas funcionais aqueles trabalhadores que não fossem fumantes; dessa forma, através das respostas ao questionário padrão, foram eliminados do estudo os fumantes em qualquer grau. Por outro lado, tanto as fiações estudadas como a fábrica de produtos alimentícios que serviu de controle estavam expostas a condições equivalentes de poluição atmosférica.
O número total de pessoas estudadas foi o seguinte:

$\begin{array}{lr}\text { Fábrica A } & 26 \text { pessoas } \\ \text { Fábrica B } & 44 \text { pessoas } \\ \text { Fábrica C } & 29 \text { pessoas } \\ \text { Controle } & 135 \text { pessoas }\end{array}$

Portanto, o grupo exposto era composto de 99 pessoas e o controle de 135 pessoas.

As proporções das diferentes respostas aos diversos itens do questionário $\mathrm{p}$ drão, de pessoas do grupo exposto e do grupo padrão, foram comparadas através do uso de um teste de associação. Os resultados das provas de função pulmonar foram avaliadas por meio de um teste de médias considerando as populações correlatas. Todas as decisões foram tomadas a um nvel de significância igual a $5 \%$.

\section{RESULTADOS E COMENTÁRIOS}

Na Tabela 1 estão assinaladas as quantidades de poeira (poeira total e fração respirável) encontradas nos locais de trabalho das fiações de algodão.

Como seria de se esperar, na fábrica $\mathrm{A}$, dotada de moderno sistema de ventilação local exaustora, os valores encontrados foram os mais baixos do grupo. Assim, a quantidade da fração respirável era de apenas $0,266 \mathrm{mg} / \mathrm{m}^{3}$ de ar nas cardas e de $0,186 \mathrm{mg} / \mathrm{m}^{3}$ de ar na preparação. Pelo contrário, na fábrica $\mathbf{B}$ foram encontrados os valores mais elevados, com $2,351 \mathrm{mg} / \mathrm{m}^{3}$ de ar nas cardas e $1,500 \mathrm{mg} / \mathrm{m}^{3}$ de ar na preparação, evidenciando a importância das medidas que a empresa estava levando a cabo, no momento da pesquisa, no sentido de

* Comunicação pessoal. 
NOGUEIRA, D. P. et al. - Bissinose no município da capital do Estado de São Paulo, Brasil. Rev. Saúde puibl., S. Paulo, 7:251-72, 1973.

dotar as máquinas de um sistema ventilatório exaustor que permitisse ređução das elevadas concentrações de poeira ali encontradas. $\mathrm{Na}$ fábrica $\mathrm{C}$, finalmente, a despeito de tratar-se de fiação tradi- cional, mas graças à ampla ventilação natural ali existente, os valores encontrados eram de $1,166 \mathrm{mg} / \mathrm{m}^{3}$ de ar na sala de cardas e $0,525 \mathrm{mg} / \mathrm{m}^{3}$ de ar na de preparação.

T A

Concentrações de poeira respirável de algodão nas seções, conforme as seções e segundo as empresas estudadas

\begin{tabular}{|c|c|c|c|c|}
\hline \multirow{3}{*}{ Empresa } & \multicolumn{4}{|c|}{ seço es } \\
\hline & \multicolumn{2}{|c|}{ Cardas } & \multicolumn{2}{|c|}{ Preparacăo } \\
\hline & $\begin{array}{l}\text { Poeira total } \\
\mathrm{mg} / \mathrm{m} 3\end{array}$ & $\begin{array}{c}\text { Fração respirável } \\
\mathrm{mg} / \mathrm{m} 3\end{array}$ & $\begin{array}{l}\text { Poeira total } \\
\mathrm{mg} / \mathrm{m} 3\end{array}$ & $\begin{array}{c}\text { Fração respirável } \\
\mathrm{mg} / \mathrm{m} 3\end{array}$ \\
\hline $\mathbf{A}$ & 0,428 & 0,266 & 0,722 & 0,186 \\
\hline $\mathbf{B}$ & 3,639 & 2,351 & 2,809 & 1,500 \\
\hline $\mathbf{C}$ & 2,027 & 1,166 & 1,243 & 0,525 \\
\hline
\end{tabular}

Conforme se verifica pela Tabela 2, na fábrica $\mathrm{A}$ o número de trabalhadores estudados expostos à poeira de algođão era de 26 , sendo $4(15,38 \%)$ nas cardas e $22(84,62 \%)$ na preparação. Na fábrica $B$ tais números eram, respectivamente, de $14(31,82 \%)$ e $30(68,18 \%)$ e, na fábrica C, de $5(17,24 \%)$ e $24(82,76 \%)$. Portanto, do total de 99 pessoas que trabalhavam expostas à poeira de algodão, $23(23,23 \%)$ trabalhavam nas cardas e $76(76,77 \%)$ na preparação.

As características quanto à idade, raça, estado civil e sexo da amostra estudada, inclusive do grupo controle, estão assinalados na Tabela 3 . Verifica-se que tais características se distribuem de maneira apreciavelmente uniforme entre os dois grupos, exposto e controle. Há a se destacar que no grupo controle, nota-se discreta predominância de indivíduos da raça negra e do sexo masculino.
T A B E L A 2

Distribuição dos trabalhadores estudados de acordo com a empresa e segundo a seção em que trabalha

\begin{tabular}{|c|c|c|c|}
\hline \multirow{2}{*}{ Empresas } & \multicolumn{3}{|c|}{ Seções } \\
\hline & Cardas & Preparação & TOTAL \\
\hline A & $\begin{array}{c}(15,38) \\
4\end{array}$ & $\begin{array}{c}(84,62) \\
22\end{array}$ & $\begin{array}{c}(100,00) \\
26\end{array}$ \\
\hline B & $\begin{array}{c}(31,82) \\
14\end{array}$ & $\begin{array}{c}(68,18) \\
30\end{array}$ & $\begin{array}{c}(100, c 0) \\
44\end{array}$ \\
\hline $\mathbf{C}$ & $\begin{array}{c}(17,24) \\
5\end{array}$ & $\begin{array}{c}(82,76) \\
24\end{array}$ & $\begin{array}{c}(100,00) \\
29\end{array}$ \\
\hline TOTAL & $\begin{array}{c}(23,23) \\
23\end{array}$ & $\begin{array}{c}(76,77) \\
76\end{array}$ & $\begin{array}{c}(100,00) \\
99\end{array}$ \\
\hline
\end{tabular}

O questionário veio mostrar que a maioria dos empregados $(42,6 \%)$ tinha iniciado a exposição à poeira de algodão 


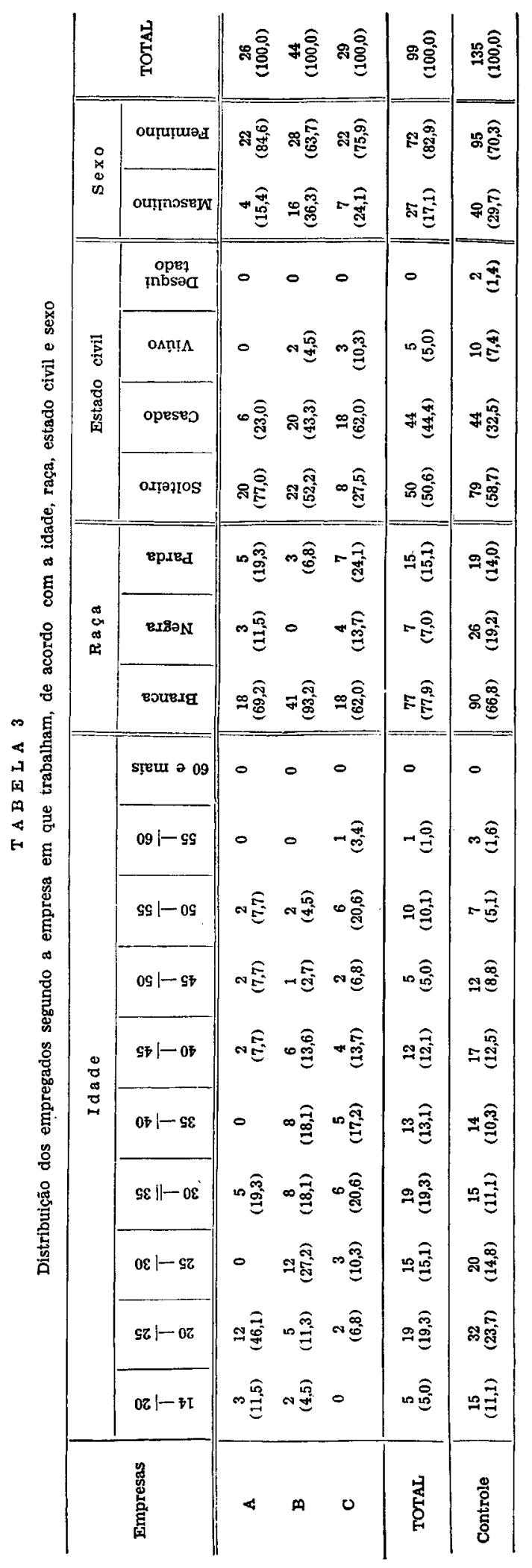


NoGuetra, D. P. et al. - Bissinose no município da capital do Estado de São Paulo, Brasil. Rcv. Saúde públ., s. Paulo, 7:251-72, 1973.

com menos de 20 anos de idade (Tabela 4); tal fato era especialmente marcante em relação à fábrica $A$, na qual esse valor atingira $73,3 \%$. A grande maioria dos trabalhadores $(63,6 \%)$ informava que tal exposição durava 5 anos e mais (Tabela 5 ).

Será interessante observar (Tabela 4) que entre os trabalhadores do grupo controle 15 pessoas $(11,1 \%)$ referiam ter tido exposição anterior à poeira de algodão, que na maioria dos casos $(73,3 \%)$ também ocorrera com menos de 20 anos de idade e que durara em mais da metade $(\mathbf{5 3 , 5} \%$ dos casos) um período de 1 a 4 anos.

T A B E L A 4

Distribuição dos empregados segundo a empresa em que trabalham, de acordo com a idade em que ocorreu a primeira exposição à poeira de algodão

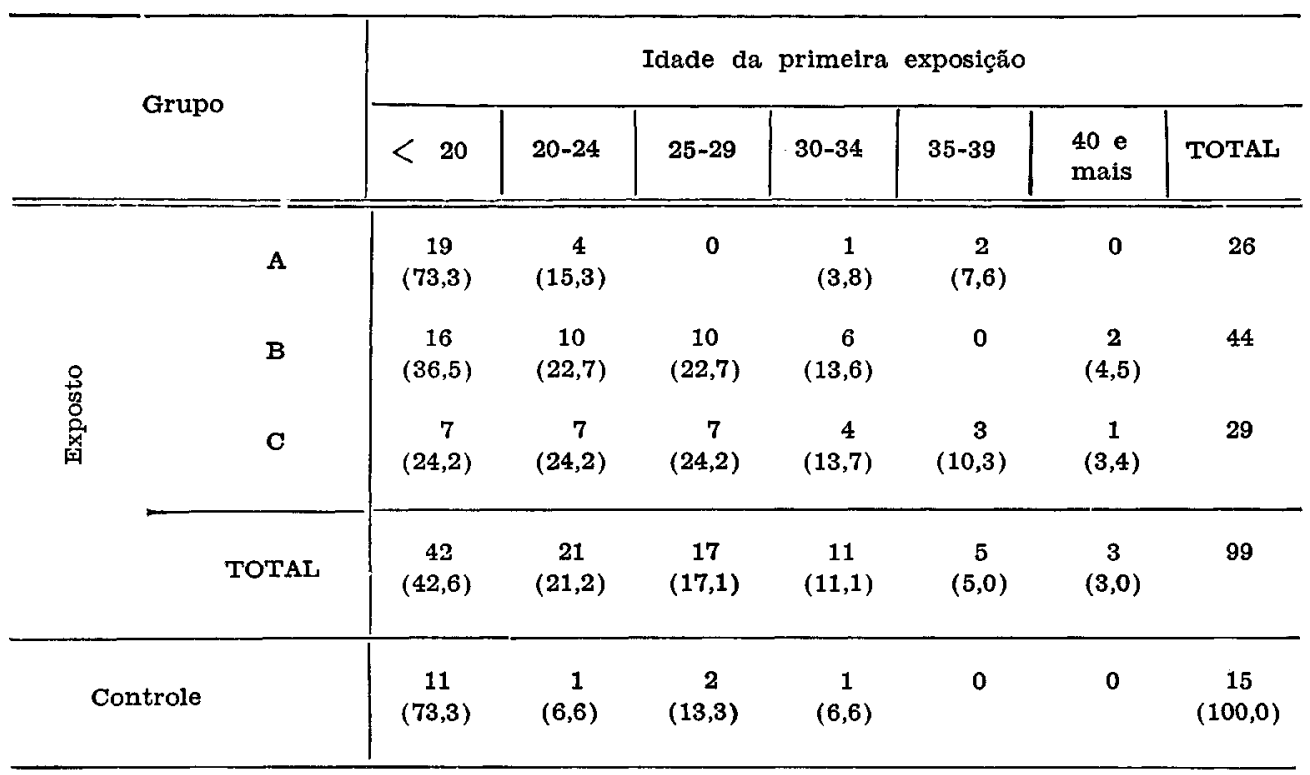

O questionário veio mostrar que a sensação de constrição torácica não era referida por nenhum trabalhador da fábrica $A$, enquanto que o era por 11 da fábrica $B$, por 7 da fábrica $C$ e por 9 do grupo controle (Tabela 6). $O$ teste de associação revela que a proporção de empregados das fábrica $\mathbf{B}$ e $\mathbf{C}$ com o sintoma mais conhecido da bissinose é significantemente maior do que no grupo controle, não sendo isto constatado a propósito dos trabalhadores pertencentes à fábrica $\mathrm{A}$.
A tosse durante a manhã (Tabela 6) foi encontrada em 9 trabalhadores da fábrica $\mathrm{A}$, em 24 da $\mathrm{B}$, em 8 da $\mathrm{C}$ e em 11 do grupo controle, sendo significante a associação positiva entre este sinal $e$ as fábricas B e C. Os trabalhađores destas fábricas referiam a persistência do sintoma em 6 casos na fábrica $A$, 19 casos na fábrica $B, 7$ casos na fábrica C e 8 casos no grupo controle; as proporções foram significantemente mais elevadas nas fábricas $\mathrm{B}$ e $\mathrm{C}$ do que no grupo controle. Os trabalhadores destas 
NOGUEIRA, D. P. et al. - Bissinose no município da capital do Estado de Săo Paulo, Brasil. Rev. Saúde públ., S. Paulo, 7:251-72, 1973.

T A B E L A 5

Distribuição dos empregados segundo a empresa em que trabalham, de acordo com o número de anos de exposição à poeira de algodão

\begin{tabular}{|c|c|c|c|c|c|c|c|}
\hline \multirow{2}{*}{\multicolumn{2}{|c|}{ Grupo }} & \multicolumn{6}{|c|}{ Número de anos de Exposição } \\
\hline & & -1 & $1-4$ & $5-9$ & $10-19$ & $20 \mathrm{e}+$ & TOTAL \\
\hline \multirow{4}{*}{ 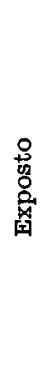 } & A & 0 & $\begin{array}{c}8 \\
(30,9)\end{array}$ & $\begin{array}{c}9 \\
(34,6)\end{array}$ & $\begin{array}{c}3 \\
(11,5)\end{array}$ & $\begin{array}{c}6 \\
(23,0)\end{array}$ & 26 \\
\hline & B & $\begin{array}{c}7 \\
(15,9)\end{array}$ & $\begin{array}{c}11 \\
(25,0)\end{array}$ & $\begin{array}{c}14 \\
(32,0)\end{array}$ & $\begin{array}{c}8 \\
(18,1)\end{array}$ & $\begin{array}{c}4 \\
(9,0)\end{array}$ & 44 \\
\hline & $\mathbf{C}$ & $\begin{array}{c}3 \\
(10,3)\end{array}$ & $\begin{array}{c}6 \\
(20,6)\end{array}$ & $\begin{array}{c}3 \\
(10,3)\end{array}$ & $\begin{array}{c}8 \\
(27,5)\end{array}$ & $\begin{array}{c}9 \\
(31,3)\end{array}$ & 29 \\
\hline & TOTAL & $\begin{array}{c}10 \\
(10,1)\end{array}$ & $\begin{array}{c}25 \\
(25,3)\end{array}$ & $\begin{array}{c}26 \\
(26,4)\end{array}$ & $\begin{array}{c}19 \\
(91,1)\end{array}$ & $\begin{array}{c}19 \\
(19,1)\end{array}$ & 99 \\
\hline \multicolumn{2}{|c|}{ Controle } & $\begin{array}{c}5 \\
(33,3)\end{array}$ & $\begin{array}{c}8 \\
(53,5)\end{array}$ & $\begin{array}{c}1 \\
(6,6)\end{array}$ & $\begin{array}{c}1 \\
(6,6)\end{array}$ & 0 & $\begin{array}{c}15 \\
(100,0)\end{array}$ \\
\hline
\end{tabular}

T A B E L A 6

Distribuição dos empregados segundo a empresa em que trabalham, de acordo com a sensação de constrição torácica às segundas-feiras, tosse e escarro

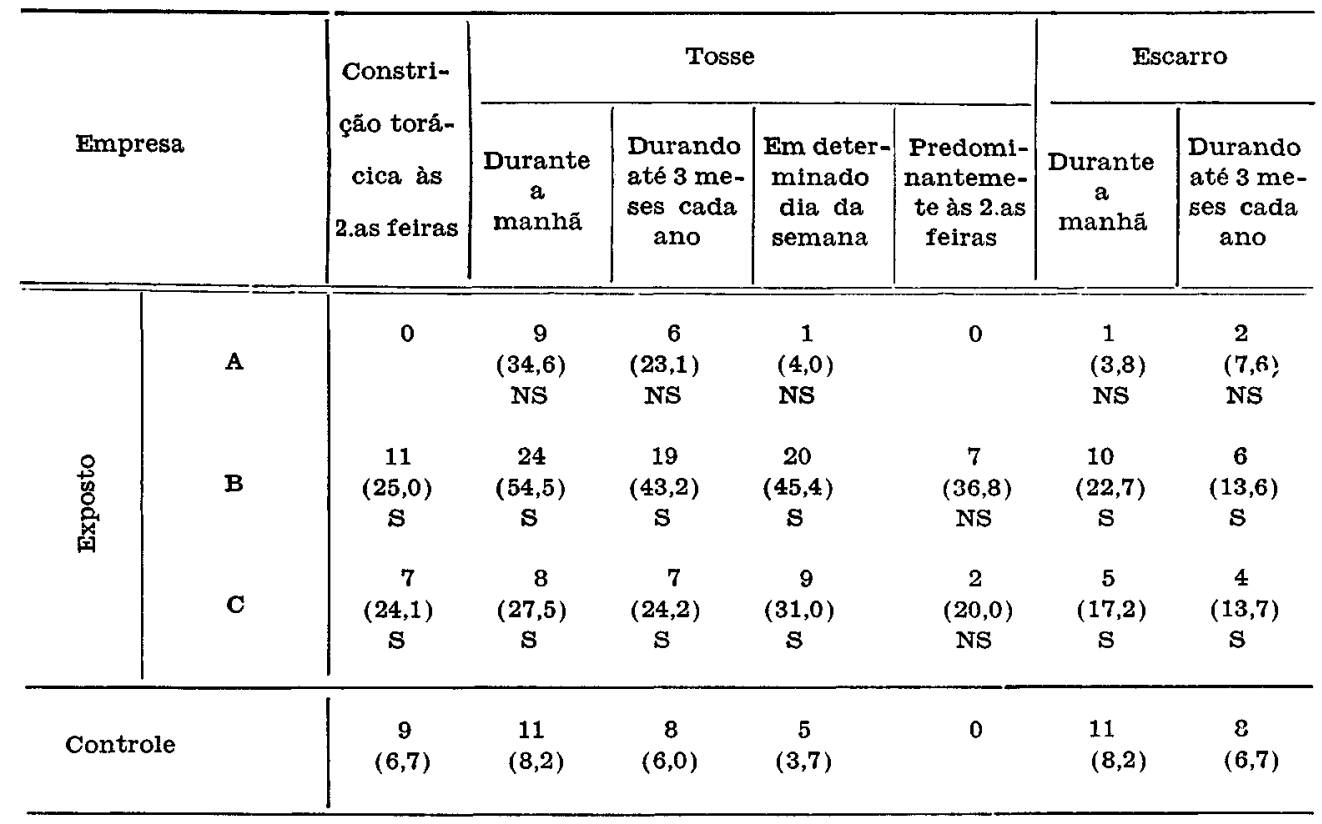


Nogueira, D. P. et al. - Bissinose no município da capital do Estado de são Paulo, Brasil. Rev. Saúde puibl., S. Paulo, 7:251-72, 1973.

duas últimas fábricas revelavam a predominância da tosse em determinado dia da semana respectivamente em 20 e em 9 casos, sendo significante a associação, o que não era verificado quanto aos empregados da fábrica $\mathrm{A}$.

Em nenhuma das fábricas a predominância da tosse às segundas-feiras ocorreu numa proporção de empregados que diferisse significantemente de zero (registrada no grupo controle).

Escarro durante a manhã foi encontrado em um caso da fábrica $A$, em 10 da B, em 5 da $C$ e em 11 do grupo controle, sendo significante a associação positiva entre a presença deste sinal e as fábricas B e C. Persistia durante até 3 meses em cada ano em 2 trabalhadores da fábrica $A$, em 6 da fábrica $B$, em 4 da fábrica $\mathrm{C}$ e em 8 do grupo controle, sendo as proporções de empregados com a persistência de até 3 meses significantemente maior nas amostras das fábricas B e C em relação ao grupo controle.

Dos resultados obtidos através do questionário, um fato se torna evidente: a sintomatologia característica da bissinose não foi encontrada em proporções significantemente maiores do que as registradas no grupo controle quando estudada a fábrica $\mathrm{A}$, tendo ocorrido isto, quando consideradas as fábricas $B$ e C. Como seviu atrás, a fábrica A é aquela que apresenta os mais baixos valores da fração respirável da poeira de algodão, pelo que parece lcito concluir-se que estes últimos são os responsáveis pela não significância dos sintomas; tal conclusão contradiz a opinião de Bounurs ${ }^{2}$, que é de opinião de que não existe relação entre a quantidade de poeira de algodão existente na atmosfera dos locais de trabalho e a incidência da bissinose.
Os resultados das provas de função pulmonar encontram-se assinalados na Tabela 7 sob a forma de média e desvio padrão das diferenças entre os valores correspondentes às provas realizadas imediatamente antes e imediatamente depois do período de trabalho, assim como o teste de médias considerando as populações correlatas.

O volume expiratório máximo em um segundo (VEM $\left.{ }_{1,0}\right)$ mostrou alteração significativa somente na fábrica $B$, ou seja, o valor obtido imediatamente após o período de trabalho mostrou-se significantemente alterado, evidenciando uma alteração da função pulmonar no fim do primeiro dia de trabalho da semana (segunda-feira); nas duas outras fábricas as alterações observadas não foram significantes. No entanto, o grupo controle sugere uma alteração significante no sentido inverso após o término do dia de trabalho, ou seja, o VEM ${ }_{1,0}$ medido no término do primeiro dia de trabalho da semana, parece significantemente aumentado em relação àquele obtido antes do início do trabalho.

A capacidade vital forçada (CVF) também mostrou-se significantemente alterada nos trabalhadores da fábrica $B$, não mostrando alterações significativas quer em relação aos demais componen. tes do grupo exposto, quer em relação ao grupo controle nas fábricas $\mathbf{A}$ e $\mathbf{C}$.

$O$ indice de Tiffeneau não mostrou alteração significativa em relação ao grupo exposto, mas também sugere melhora significante no grupo controle.

O fluxo expiratório máximo (FEM) mostrou-se também alterado significantemente em relação aos trabalhadores da fábrica $B$, não mostrando alterações significantes nos demais membros do grupo exposto. Ainda aqui o grupo controle mostrou alteração significativa para mais ao fim do período de trabalho. 


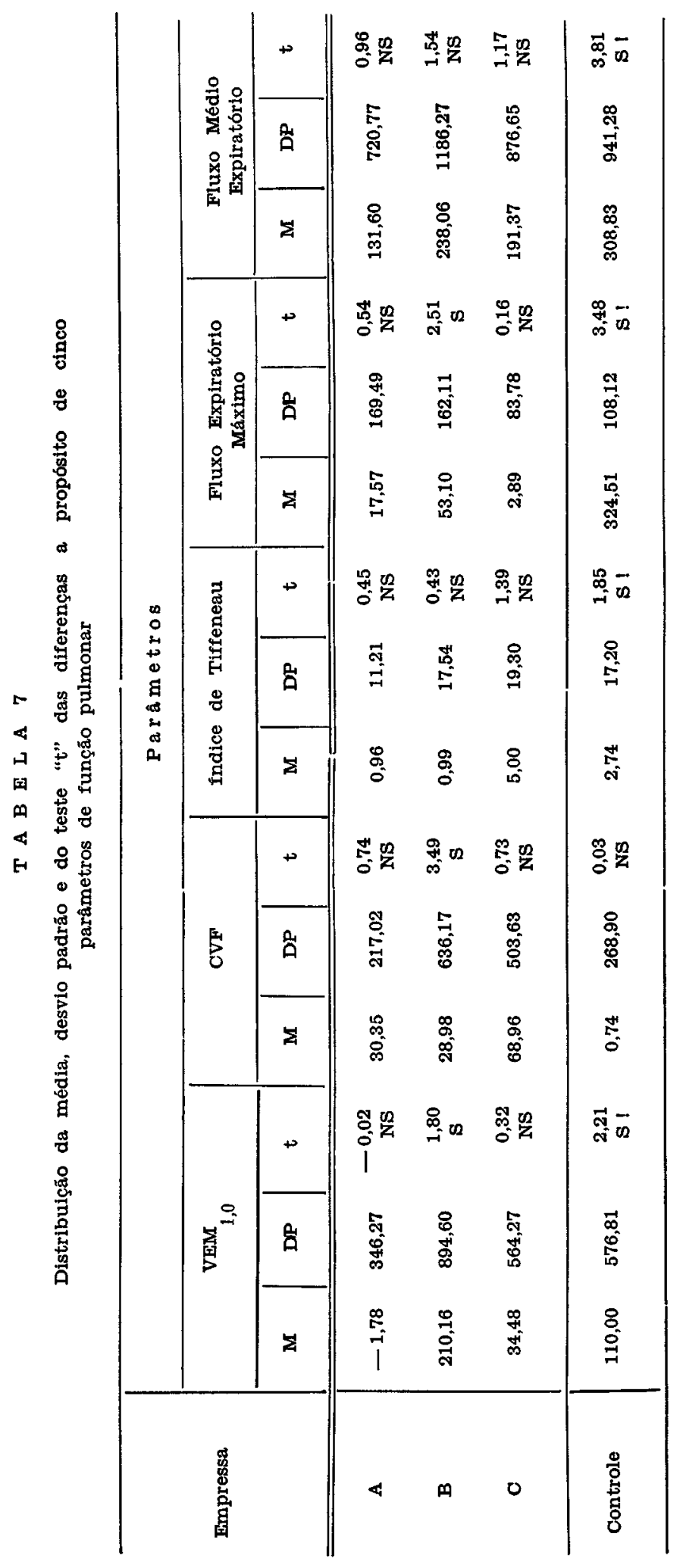


NOGUEIRA, D. P. et al. - Bissinose no municipio da capital do Estado de são Paulo, Brasil. Rev. Saúde públ., S. Paulo, 7:251-72, 1973.

O fluxo médio expiratório, finalmente, não revelou alteração significativa no grupo exposto, mas também apresentou melhoria significativa no grupo controle.

Verifica-se, pois, que os parâmetros respiratórios medidos não mostraram alteração significativa nas fábricas $\mathrm{A}$ e C, mas mostraram-se significantemente reduzidos - com exceção do índice de Tiffeneau e do fluxo médio expiratório - nos trabalhadores da fábrica B. Como essa fábrica foi a que apresentou maior concentração de poeira de algođão em suspensão na atmosfera dos locais de trabalho, confirma-se o que foi verificado em relação às respostas ao questionários, ou seja, que existe relação entre concentração de poeira e alterações funcionais pulmonares.

As alteraçóes para mais de praticamente todos os parâmetros respiratórios, com exceção da CVF, é decorrência provável do ciclo circadiano. Assim, Conroy \& Mills $^{3}$, em revisão bibliográfica, afirmam que a $\mathrm{CV}$ e o FEV aumentam progressivamente, a primeira a partir da meia-noite e o segundo a partir das 06,00 horas.

Esse aumento significativo das provas de função pulmonar, em função do ritmo circadiano, nos trabalhadores do grupo exposto conduz a uma indagação importante: porque tal alteração não foi observada nos trabalhadores das fábricas $A$ e C? Poder-se-ia, portanto, supor que a não existência do aumento significativo de tais parâmetros já representa uma alteração, por mínima que seja, da função pulmonar; assim, tais trabalhadores, expostos a concentrações não muito ele. vadas de poeira de algodão, não apresentam redução significativa da sua função pulmonar; esta, porém, já estaria sofrendo a influência da poeira em suspensão nos ambientes de trabalho e, dessa forma, não consegue melhorar em fun- ção do ritmo circadiano, como seria de se esperar.

\section{CONCLUSOES}

Da pesquisa levada a cabo as seguintes conclusões podem ser tiradas.

1. A exposição à poeira de algođão provoca em trabalhadores brasileiros a mesma sintomatologia e as mesmas alterações funcionais pulmonares já observadas por vários autores em diversos países do mundo.

2. Parece haver correlação direta entre quantidade de poeira e o aparecimento da sintomatologia característica da bissinose e as alterações da função pulmonar.

3. O VEM ${ }_{1,0}$, a CVF e o FEM parecem ser os parâmetros respiratórios mais sensiveis à influência da inalação da poeira de algodão.

4. Mesmo nos trabalhadores em que não é observada redução significativa da função pulmonar, a não melhoria desta no decorrer do dia de trabalho, como ocorre em indivíduos não expostos à poeira de algodão, pode constituir um sinal precoce de alteração funcional pulmonar, ainda não descrito na literatura mundial.

\section{AGRADECIMENTOS}

Ao Prof. Dr. A. Bouhuys, pelas numerosas sugestões apresentadas à sistemática do trabalho; ao Sr. J. Lynch pela orientação no uso do elutriador vertical; ao Dr. Joaquim Augusto Junqueira, pela proposição do trabalho; aos Srs. E. Geraisate e M. Siamenghi Filho pelo trabalho na coleta de amostras de poeira e no preenchimento de questionários e realização de provas de função pulmonar; à Sra. Cleide B. Pezza pela pesagem de filtros e de trabalhos de laboratório; 
NoGueira, D. P. et al. - Bissinose no município da capital do Estado de são Paulo, Brasil. Rev. Saúde públ., S. Paulo, 7:251-72, 1973.

ao Dr. René Mendes pelo auxílio prestado na elaboração das tabelas; aos Srs. J. I. Franco, R. Fiurini e F. D. de Lima pelos trabalhos de computação de dados; e à Dra. Eunice Pinho pela orientação da realização da amostragem.

RSPU-B/176

Nogueira, D. P. et al. - [Byssinosis in the County of S. Paulo, Brazil]. Rev. Saúde públ., S. Paulo, 7: 251-72, 1973.

Summary: Workers of three cotton spinneries, with different amounts of cotton dust in the athmosphere of work places, were studied according to the epidemiological method of study proposed by Schilling, as compared with 135 workers not exposed to cotton dust. Through the answers to the international questionnaire on lung diseases, it was disclosed that workers from mills with highest concentration of cotton dust in the air presented symptoms characteristic of byssinosis; on the other hand, lung function tests performed on mondays immediately after the period of work showed impairment of lung function when compared with tests performed immediately before starting work. As in the control group lung function tests actually became better after the period of work, it is supposed that the non-existence of changes in lung function after work in mills the amount of cotton dust in the air was low-may be an indication of an early impairment of lung function due to the inhalation of cotton dust.

UNITERMS: Dust *; Pneumoconiosis *; Respiratory tract infections *.

\section{REFERENCIAS BIBLIOGRAFICAS}

1. BELIN, L. et al. - Byssinosis in cardroom workers in Swedish cotton mills - Brit. J. industr. Med., 22:101-8, 1965.

2. BOUHUYS, A. Byssinosis in textile workers. - Trnns. N. Y. Acad. Sci., 28:480-90, 1966.

3. CONROY, R. T. W. \& MILLS, J. N. Human circadian rhyths. London, Churchill, 1970.

4. EL BATAWI, M. A. - Byssinosis in the cotton industry of Egypt - Brit. J. industr. Med., 19:126-30, 1962.

5. GaNDEVIA, B. \& MILNE, J. - Ventilatory capacity changes on exposure to cotton dust and their relevance to byssinosis in Australia. Brit. J. industr. Med., 22:295-304, 1965.

6. KONDAKIS, $\mathrm{X}$. G. \& POURNARAS, N. Byssinosis in cotton ginneries in Greece. Brit. J. industr. Med., 22:291-94, 1965.
7. MC KERROW, C. B. \& SCHILLING, R. S. F. - A pilot enquiry into byssinosis in two cotton mills in the United States. J. Amer. med. Ass., 177:850-3, 1961.

8. ROACH, S. A. \& SCHILLING, R. S. F. - A clinical and environmental study of byssinosis. Brit. J. industr. Med., 1:1-9, 1960.

9. SCHILLING, R. S. F. - The epldemiology of byssinosis: adventure and $\mathrm{mis}$ adventure. $J$, occup. Med., 1:33-39,

10. SCHILLING, R. S. F. - The epidemiology on byssinosis. In: KING, E. J. \& FLETCHER, C. M. - Industrial pulmonary diseases. London, Churchill, 1960. p 185-94.

11. TUYPENS, E. - Byssinosis among cotton workers in Belgium. Brit. J. industr. Med., 18:117-9, 1961.

Recebido para publicação em 22-6-1973 Aprovado para publicação em 10-7-1973 
NOGUErRA, D. P. et al. - Bissinose no município da capital do Estado de São Paulo, Brasil. Rev. Saúde públ., S. Paulo, 7:251-72, 1973.

FACULADE DE SAÚdE PƯBLICA DA UNIVERSIDADE DE SAO PAULO DEPARTAMENTO DE SAƯDE AMBIENTAL

FUNDAÇÃO CENTRO NACIONAL DE SEGURANÇA, HIGIENE E MEDICINA DO TRABALHO

\section{QUESTIONARIO SOBRE SINTOMATOLOGIA RESPIRATORIA *}

NOME Uitimo sobrenome

NUTMERO $1-4$

Para codificar depois

Levantamento

Data da entrevista

Entrevistador

Código de domicílio

Código de idade

\section{5}

$\square \square \quad 6-7$

DOMICfLIO

Data do nascimento ${ }_{\text {Dia }} \ldots{ }_{\text {Mề }} \cdots \cdots \cdots \cdots$

Data da entrevista $\underset{\text { Dia }}{\text { Mề }}{ }_{\text {Ano }}$
RAÇA

Branca

$0 \square 16$

Preta

1

Amarela

2

Parda

Outra

3

4

ESTADO CIVIL

Solteiro

$0 \square 17$

Casado

1

Viúvo

2

Desq./Sep.

3

SEXO Masculino

$0 \square 18$

Feminino

1

SELEÇÃO Trabalhador exposto ao risco

$0 \square 19$

Controle

$1 \square$

Ex-trabalhador

* Tradução, com permissão, do questionário da John B. Pierce Foundation, Yale University, New Haven, Connecticut, USA. 
NOGUEIRA, D. P. et al. - Bissinose no município da capital do Estado de São Paulo, Brasil. Rev. Saúde públ., S. Paulo, 7:251-72, 1973.

TOSSE

1. Costuma tossir logo que acorda pela manhã?

Não 0

Sim 1

2. Costuma tossir durante o dia ou durante a noite?

Não 0

Sim 1

3. Costuma tossir dessa maneira por um período de até 3

Não $0 \square 20$ meses cada ano?

Sim 1

Não 0

Somente às segundas-feiras, algumas vezes

Somente às segundas-feiras, sempre

Somente às segundas e terças-feiras

As segundas-feiras e durante os outros dias de trabalho

Outros dias da semana que não segunda-feira

EXPECTORAÇÃO ou outro termo local (p. e., catarro)

5. Costuma expectorar logo que acorda pela manhã e a expectoração vem do peito?

Não 0

Sim 1

6. Costuma expectorar durante o dia ou durante a noite e a expectoração vem do peito?

Não 0

Sim 1

7. Costuma expectorar dessa maneira por um período de até 3 meses cada ano?

Não $0 \square 22$

Sim 1

Não $0 \square 23$

8. Já expectorou sangue alguma vez?

Sim 1

CONSTRIÇÃO TORACICA (Aperto no peito)

9. Sente alguma vez aperto no peito ou dificuldade para respirar?

Não 0

24

10. Sente aperto no peito ou dificuldade para respirar em determinado dia da semana?

Somente às segundas-feiras, algumas vezes

Somente às segundas-feiras, sempre

Somente às segundas e terças-feiras

As segundas-feiras e durante os outros dias de trabalho

Outros dias da semana que não segunda-feira

Sim 1

Não 0

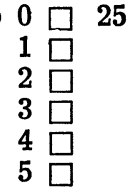

11. A que horas, nas segundas-feiras, sente aperto no peito ou dificuldade para respirar?

Das....... até às....... horas Não sabe............

Codificar posteriormente

12. A que horas, nas terças-feiras, sente aperto no peito ou dificuldade para respirar?

Das....... até às....... horas Não sabe.............

Codificar posteriormente 
NoGUEIRA, D. P. et al. - Bissinose no município da capital do Estado de São Paulo, Brasil. Rev. Saúde públ., S. Paulo, 7:251-72, 1973.

13. Se a resposta à pergunta 10 tiver sido negativa:

Sentiu alguma vez aperto no peito ou dificuldade para respirar em algum dia especial da semana?

Não $0 \square 30$

Somente às segundas-feiras, algumas vezes

1

Somente às segundas-feiras, sempre

Somente às segundas e terças-feiras

As segundas-feiras e durante os outros dias de trabalho

Outros dias da semana que não segunda-feira

DISPNEA (Falta de ar)

14. Se o indivíduo apresentar dificuldade à marcha por qualquer razão que não doença cardíaca ou pulmonar, marque 0 aqui e não faça as perguntas de 15 a 18 . Em caso contrário, marque 1 e continue a perguntar

\section{NOS FINS DE SEMANA}

15. Já sentiu alguma vez falta de ar quando andava depressa no plano ou quando subia pequena ladeira?

Não 0

Sim 1

16. Costuma sentir falta de ar quando está andando juntamente com outras pessoas, em passo normal, no plano?

Não 0

Sim 1

17. Costuma precisar parar para respirar quando está andando sozinho, normalmente, no plano?

Não 0

Sim 1

31

18. Costuma sentir falta de ar quando está se vestindo?

Não 0

Sim 1

\section{ÀS SEGUNDAS-FEIRAS}

Não codifique as perguntas de 19 a 22 para ex-trabalhadores

19. Já sentiu alguma vez falta de ar quando andava depressa no plano ou quando subia pequena ladeira?

Não 0

$\operatorname{Sim} 1$

20. Costuma sentir falta de ar quando andando juntamente com outras pessoas, em passo normal no plano?

Não $0 \square 37$

$\operatorname{Sim} 1$

21. Costuma precisar parar para respirar quando está andando sozinho, normalmente, no plano?

Não $0 \square 38$

Sim 1

Não 0

Sim 1

22. Costuma sentir falta de ar quando está se vestindo?

DOENÇAS RESPIRATORIAS (Doenças do peito)

23. Nos últimos 3 anos apresentou alguma doença respiratória (doença do peito) que o tenha impedido de trabalhar e o obrigado a ficar em casa ou na cama, ou que o tenha obrigado 
NOGUEIRA, D. P. et al. - Bissinose no município da capital do Estado de São Paulo, Brasil. Rev. Saúde puibl., S. Paulo, 7:251-72, 1973.

24. Se a resposta for afirmativa, perguntar detalhes de cada doença:

\begin{tabular}{|c|c|c|c|c|c|}
\hline \multirow{3}{*}{ Ano } & \multicolumn{2}{|c|}{ Duração da doença } & \multicolumn{2}{c|}{$\begin{array}{c}\text { Aumento da expectora- } \\
\text { ção (do escarro) }\end{array}$} & $\begin{array}{c}\text { Diagnóstico } \\
\text { feito pelo médico }\end{array}$ \\
\cline { 2 - 6 } & $\begin{array}{c}\text { 1 semana } \\
\text { ou mais }\end{array}$ & $\begin{array}{c}\text { menos de 1 } \\
\text { semana }\end{array}$ & Sim & Não & \\
\hline & & & & & \\
\hline & & & & & \\
\hline & & & & & \\
\hline
\end{tabular}

Informe o nome dos hospitais onde esteve internado para tratamento dessas doenças do peito

Registre aqui o número de crises de doença que duraram mais de

1 semana, com aumento da expectoração. Veja pergunta 24.

\section{ANTECEDENTES PATOLOGICOS}

25 Já teve alguma vez

$$
\text { Sim Não Idade }
$$
a. Bronquite
b. Pneumonia
c. Pleuris
d. Tuberculose pulmonar
e. Asma brônquica
f. Outras doenças respiratórias

$\ldots \ldots$... de.... a ....

de.... a ....

de.... a ....

26. Se a resposta à pergunta $25 \mathrm{f}$ for afirmativa, especificar as doenças 
NOGUEIRA, D. P. et al. - Bissinose no município da capital do Estado de são Paulo, Brasil. Rev. Saúde puibl., S. Paulo, 7:251-72, 1973.

Codificar posteriormente
a. - Nenhuma -
b. Somente broquite (uma única vez)
c. Somente bronquite (crises repetidas)
d. Bronquite (uma única vez) + outras doenças respiratórias
e. Bronquite (crises reptidas) + outras doenças respiratórias
f. Asma brônquica (no momento sem crises)
g. Asma brônquica (crises ainda presentes)

0

1

27. Outras doenças ou operações?

Em caso afirmativo, dar detalhes que interessem ao presente estudo:

Hospital

Duração da estadia no hospital

Duração da incapacidade

Complicações

28. Algum membro da sua família sofre de alguma destas doenças?

Por parentes considerar somente seus pais, seus irmãos e seus filhos.

Não

Asma brônquica

Asma, eczema, alergia

Bronquite

Bronquite e pneumonia

29. Algum deles, que tenha asma ou bronquite, já trabalhou com algodão/linho ou cânhamo?

30. Algum deles, mesmo sem asma ou bronquite, já trabalhou com algodão/linho ou cânhamo?

31. HISTORICO PROFISSIONAL

Dê amplos detalhes sobre os periodos em que tenha trabalhado em minas de carvão ou em outras minas, em fundições, fábricas de cerâmica, linho, cânhamo, amianto e em outras ocupações em que tenha havido exposição a poeiras e qualquer outra exposição a gases irritantes ou vapores químicos.

\begin{tabular}{|l|l|l|l|l|}
\hline Ano & Domicílio & Indústria & Tipo de trabalho & Tipo da indústria \\
\hline \hline & & & & \\
\hline & & & & \\
\hline
\end{tabular}


NOGUEIRA, D. P. et al. - Bissinose no município da capital do Estado de São Paulo, Brasil. Rev. Saúde puibl., S. Paulo, 7:251-72, 1973.

Codificar a partir da hsitória profissional (pergunta 31)

32. Exposição na indústria de algodão/linho/cânhamo

$\begin{array}{ll}\text { Não } & 0 \square 47 \\ \text { Algodão } & 1 \square \\ \text { Cânhamo } & 2 \square \\ \text { Linho } & 3 \square \\ \text { Combinação dessas fibras téxteis } & 4 \square \\ \text { Outras fibras téxteis } & 5 \square\end{array}$

33. Idade em que ocorreu a primeira exposição na indústria de algodão/linho/cânhamo

$\begin{array}{ll}<20 & 0 \square 48 \\ 20-24 & 1 \square \\ 25-29 & 2 \square \\ 30-34 & 3 \square \\ 35-39 & 4 \square \\ 40+ & 5 \square\end{array}$

34. Número de anos de exposição na indústria de algodão/linho/cânhamo

$\begin{array}{cl}\text { Não } & 0 \square 49 \\ <1 \text { ano } & 1 \square \\ 1-4 & 2 \square \\ 5-9 & 3 \square \\ 10-19 & 4 \square \\ 20+ & 5 \square\end{array}$

35. Número de anos decorridos desde a última exposição na indústria de algodão/linho/cânhamo

$\begin{array}{cl}\text { Não } & 0 \square \mathbf{5 0} \\ <1 \text { ano } & 1 \square \\ 1-4 & 2 \square \\ 5-9 & 3 \square \\ 10-19 & 4 \square \\ 20+ & 5 \square\end{array}$

36. Número de anos de exposição em ocupações com poeiras, gases irritantes ou vapôres químicos

$\begin{array}{cl}\text { Não } & 0 \square 51 \\ <1 \text { ano } & 1 \square \\ 1-4 & 2 \square \\ 5-9 & 3 \square \\ 10-19 & 4 \square \\ 20+ & 5 \square\end{array}$


NOGUEIRA, D. P. et al. - Bissinose no município da capital do Estado de São Paulo, Brasil. Rev. Saúde puibl., S. Paulo, 7:251-72, 1973.

37. Fuma?

Considere afirmativa a resposta se o indivíduo fumava de

Não 0 52 maneira regular até há 1 mês atrás

Sim 1

Se a resposta à pergunta 37 for negativa, perguntar:

38. Já fumou alguma vez em sua vida?

Considere a resposta negativa se o indivíduo tiver fumado menos de um cigarro por dia ou menos de 28 gramas de fumo

Não 0 por mês durante um período não superior a um ano

Sim 1

53

39. Se a resposta a 37 ou 38 for afirmativa, preencha com números as caselas abaixo.

\begin{tabular}{|c|c|c|c|c|}
\hline & \multicolumn{2}{|c|}{ ATUALMENTE } & \multicolumn{2}{|c|}{ ANTERIORMENTE } \\
\hline & $\begin{array}{l}\text { Quanti- } \\
\text { dade }\end{array}$ & $\begin{array}{l}\text { Desde } \\
\text { quando }\end{array}$ & $\begin{array}{l}\text { Quanti- } \\
\text { dade }\end{array}$ & $\begin{array}{c}\text { Desde } \\
\text { quando }\end{array}$ \\
\hline \multicolumn{5}{|c|}{$\begin{array}{l}\text { Cigarros por dia (valor médio, } \\
\text { inclusive em fins de semana) }\end{array}$} \\
\hline \multicolumn{5}{|c|}{$\begin{array}{l}\text { Gramas de fumo por dia } \\
\text { (cigarros feitos a mão) }\end{array}$} \\
\hline \multicolumn{5}{|c|}{$\begin{array}{l}\text { Gramas de fuma por dia } \\
\text { (Cachimbo) }\end{array}$} \\
\hline \multicolumn{5}{|l|}{$\begin{array}{l}\text { Charutos por semana } \\
\text { (tamanho grande) }\end{array}$} \\
\hline $\begin{array}{r}\text { Charutos por semana } \\
\text { (tamanho pequeno) }\end{array}$ & & & & \\
\hline
\end{tabular}

Codificar posteriormente

Registre o consumo médio semanal em gramas

1 cigarro = equivale a 1 grama

$$
\begin{aligned}
& \text { Nenhum } \\
& 7 \text { - } 49 \text { gramas/semana } \\
& 50 \text { - } 104 \text { gramas/semana } \\
& 105 \text { - } 168 \text { gramas/semana } \\
& 169 \text { - gramas/semana }
\end{aligned}
$$$$
0 \square 54
$$$$
1
$$$$
2
$$$$
3
$$ 
NoGueIRA, D. P. et al. - Bissinose no município da capital do Estado de São Paulo, Brasil. Rev. Saúde públ., S. Paulo, 7:251-72, 1973.

40. Idade em que começou a fumar de maneira regular

41. Idade em que deixou de fumar de maneira regular

42. Se deixou de fumar ou se está fumando menos do que antes, explicar as razões pelo que está fazendo

Codificar posteriormente

Número de anos durante os quais fumou regularmente

$\begin{array}{ll}\text { Nenhum } & 1 \square 55 \\ <1 \text { ano } & 1 \square \\ 1-4 & 2 \square \\ 5-9 & 3 \square \\ 10-19 & 4 \square \\ 20+ & 5 \square\end{array}$

Número de anos decorridos desde que parou de fumar

$\begin{array}{ll}\text { Nenhum } & 0 \square 56 \\ <1 \text { ano } & 1 \square \\ 1-4 & 2 \square \\ 5-9 & 3 \square \\ 10-19 & 4 \square \\ 20+ & 5 \square\end{array}$


NOGUETRA, D. P. et al. - Bissinose no município da capital do Estado de São Paulo, Brasil. Rev. Saúde públ., S. Paulo, 7:251-72, 1973.

\section{PROVAS DE FUNÇAO PULMONAR}

1. Nome

2. Número de exame

3. Altura

4. Peso

Capacidade Vital

Aparelho $n .{ }^{\circ} . . . .$. Data..../.../19... Hora do dia........hs.......min.

1.

2.

3.

4.

VOLUME EXPIRATORIO FORÇADO (1 segundo)

DATA

HORA

CONDIÇÃO

MEDIA DOS 2 VA-

LORES MAIS ALTOS

\begin{tabular}{l|l|l|}
\hline & & \\
\hline $\mathbf{1 .}$ & & \\
\hline $\mathbf{2 .}$ & & \\
\hline $\mathbf{3 .}$ & & \\
\hline $\mathbf{4 .}$ & & \\
\hline $\mathbf{5 .}$ & & \\
\hline & & \\
\hline
\end{tabular}

APARELHO

NUMERO 